\title{
Numerical investigation of vortex formation in water intake system of a pumping station during low and high tides
}

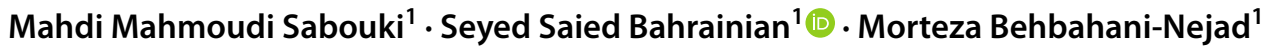

Received: 29 August 2020 / Accepted: 22 December 2020 / Published online: 11 January 2021

(c) The Author(s) 2021 OPEN

\begin{abstract}
The performance of pumps installed in pumping stations depends greatly on vortex formation at pipe intakes. Using numerical simulations and experimental methods, this study focuses on vortex formation in water intake system of a pumping station under the tidal conditions of the Bahmanshir River. The intake system consisted of a suction pipe and a fine intake screen. Realizable $k-\varepsilon$ turbulence model together with volume of fluid (VOF) two-phase (water-air) model are used to simulate the flow field in the water intake system. Vortex formation, flow pattern and flow uniformity are investigated. Water levels and free surface velocities of the river are measured in a 1-year period. The water levels range from 2.1 to $4.9 \mathrm{~m}$ and the corresponding free surface velocity varies from 1.05 to $2.35 \mathrm{~m} / \mathrm{s}$. The numerical results show that two wall-attached vortices permanently stretched to the intake screen. Additionally, two symmetrical vortices with different intensities formed in the intake screen. As the submergence of the intake pipe decreases during low tides, stronger vortices arise in the screen. Analysis of the velocity uniformity shows low level of flow uniformity at the pump intake. Low level of uniformity is attributed to the existence of the intake screen and its check valve, which facilitates the formation of vortices in the suction pipe. Based on present analysis, recommendations for modifications and improvements to the design of the pumping station are presented.
\end{abstract}

Keywords Vortex formation · Pump intake · Volume of fluid (VOF) · Intake screen · Numerical simulation

\section{List of symbols}

A Area $\left(\mathrm{m}^{2}\right)$

$G_{k} \quad$ Generation of turbulence kinetic energy due to the mean velocity gradients

$g \quad$ Gravitational acceleration $\left(\mathrm{m} / \mathrm{s}^{2}\right)$

$i, j \quad$ Indices

$k \quad$ Turbulence kinetic energy $\left(\mathrm{m}^{2} / \mathrm{s}^{2}\right)$

$P \quad$ Pressure $\left(\mathrm{N} / \mathrm{m}^{2}\right)$

$S \quad$ Source term

$T \quad$ Time (s)

$U_{p} \quad$ Bulk velocity in the pump column $(\mathrm{m} / \mathrm{s})$

$u_{i}^{\prime} \quad$ FLUCTUATION value of the velocity components $(\mathrm{m} / \mathrm{s})$ $\bar{u}_{i} \quad$ Mean velocity component $(\mathrm{m} / \mathrm{s})$

\begin{tabular}{|c|c|}
\hline$V_{x^{\prime}} V_{y^{\prime}}, V_{z}$ & $\begin{array}{l}\text { Velocity components in } \mathrm{X}, \mathrm{Y}, \mathrm{Z} \text { direction } \\
\text { accordingly }(\mathrm{m} / \mathrm{s})\end{array}$ \\
\hline$V_{\theta}$ & Tangential velocity $(\mathrm{m} / \mathrm{s})$ \\
\hline$X, Y, Z$ & Cartesian coordinates \\
\hline$\Gamma$ & Circulation $\left(\mathrm{m}^{2} / \mathrm{s}\right)$ \\
\hline$\varphi$ & Scalar parameter \\
\hline$P$ & Density $\left(\mathrm{kg} / \mathrm{m}^{3}\right)$ \\
\hline$\mu$ & Viscosity coefficient $\left(\mathrm{kg} \mathrm{m}^{-1} \mathrm{~s}^{-1}\right)$ \\
\hline$\mu_{t}$ & Turbulence viscosity $\left(\mathrm{kg} \mathrm{m}^{-1} \mathrm{~s}^{-1}\right)$ \\
\hline$\delta$ & Kronecker symbol (-) \\
\hline$\varepsilon$ & Turbulent dissipation rate $\left(\mathrm{m}^{2} / \mathrm{s}^{3}\right)$ \\
\hline$\sigma_{k}$ & Turbulence Prandtl number for $k(-)$ \\
\hline$\sigma_{\varepsilon}$ & Turbulence Prandtl number for $\varepsilon(-)$ \\
\hline$a_{q}$ & Volume fraction (-) \\
\hline & Uniformity of the flow (-) \\
\hline
\end{tabular}

Seyed Saied Bahrainian, bahrainian@scu.ac.ir; Mahdi Mahmoudi Sabouki, Mahdi.Sabuki@gmail.com; Morteza Behbahani-Nejad, bnmorteza@scu.ac.ir| 'Department of Mechanical Engineering, Shahid Chamran University of Ahvaz, Ahvaz, Iran. 


\section{Introduction}

Pumping stations play an important role in providing water for industrial, agricultural and domestic applications. Water Pumping stations are usually designed for pumping water from a water source such as a river into a supply system or elevated water tank. The pumping stations constructed near tidal rivers are facing many problems. In such pumping stations, pump performance and efficiency greatly depend on the flow field in the pump intake bay. Insufficient pump intake submergence during tides, non-uniform flow in water intake structure, as well as poor design of facilities for water transportation to the pump sumps may result in vortex formation. The formation of vortices in the pump intake will harmfully affect the pump performance. These vortices have nonsymmetrical pressure distribution, which varies from the center of the core to the perimeter. Once the vortices reach the pump impeller, non-symmetrical pressure distribution on the impeller surface may increase vibration and damage the bearings. On the other hand, free surface vortices usually contain air in their core. The pressure reduction in the core of each vortex together with the pressure reduction in the water intake system during low tides can lead to cavitations' phenomenon, which in turn causes unexpected vibrations, reduced flow, erosion of the impeller, seal and bearing failure and high power consumption. Since these problems reduce the pump efficiency and increase the maintenance costs, understanding the flow conditions in water intake system and pump sump structure is necessary. Since the study of NPSH variations is out of the scope of this paper, the main objective of this research is to determine the vortex formation in the water intake system of the Bavi pumping station. The Bavi pumping station considered in this study is located in the south west of Iran and constructed at one bank of the Bahmanshir River. The Bahmanshir River flows into the Persian Gulf. The water level in the river varies widely (as much as about $3 \mathrm{~m}$ ) due to high and low tides of the Persian Gulf.

Due to the difficulties associated with the scaled physical models (which are expensive and time consuming), and the complexity of the vortex formation at pump intakes, numerical simulation can be used as alternative to study vortex formation. Many researchers have tried to describe flow characteristics inside the water intake structures of pumping stations using computational fluid dynamics (CFD) methods [1-9]. Constantinescu and Patel developed a numerical model and simulated threedimensional flow field in a pump intake [1]. For the first time, their work represented a significant advance over previous works that studied the formation of vortices in fluid flow. The authors employed Reynolds-averaged
Navier Stokes equations together with $k-\varepsilon$ turbulence model and showed that this numerical model can predict the location and strength of free surface and wallattached vortices.

Within the past decade, flow visualization and measurement methods have advanced and helped researchers to analyze the flow field more accurately. Rajendran et al. established a benchmark study for the flow in a sump model by comparing experimental data with numerical results solving Reynolds-averaged Navier Stokes (RANS) equations with a near-wall turbulence model [2]. Their numerical results predict that the general structure, location, and number of vortices are comparable with those observed in experiments. Generally, the predicted vortices are larger yet weaker than the measured ones. The differences are due to the unsteady flow and inadequacy of the turbulence model that they used. The turbulence models used as well as the wall roughness influence the location, size, and strength of different types of vortices in the suction pipe. They continued their research and showed that vortex features within water pump intakes (such as circulation, size, and location) are time dependent [10]. Constantinescu and Patel continued their previous research and found that the $k-\varepsilon$ and $k-\omega$ turbulence models predict vortices of similar shape and size, but different locations and strength [3].

Wei and Shih employing the large eddy simulation (LES) turbulence model [4] and investigated the effect of viscosity on the prediction of flow patterns in an intake model. Large eddy simulation results showed that viscosity affects the flow patterns. When viscosity is considered, quantitative evaluation of flow velocity distribution is more accurate. Using the standard $k-\varepsilon$ turbulence model Li et al. simulated three-dimensional flow in an intake model [5]. They have compared simulation results with experimental data and showed that the numerical model can predict the general structures of vortices in the suction pipes. Turbomachinery Society of Japan (TSJ) has developed the standard test of pump sump model and investigated the prediction of flow field in the sump model using several commercial CFD codes [11]. The uniformity of pump intake flow highly affects the performance of pumps. Choi et. al. discussed the flow uniformity in a multi-intake pump sump model with seven pump intakes [12]. They showed that high level of non-uniformity is due to the non-uniform flow velocity at the inlet of the pump intake, which can cause higher value of vorticity in a multi-intake pump sump.

Because of high and low tides, the pumping stations that are near tidal rivers are facing many problems. In such pumping stations during tides, the possibility of vortex formation in the pipe intake increases as the submergence of the intake decreases in the pump intake bay [13-18]. Furthermore, pipe intakes are typically equipped with screens 
for removal of suspended solids. Selecting the appropriate screen size and type depends on flow rate and the actual size of the suspended solids. Typically, screens are categorized as coarse and fine screens. Coarse screens have openings range from 5.1 to $15.2 \mathrm{~cm}$ while fine screens have openings within the range of $0.24-0.48 \mathrm{~cm}$ [19]. Sudden pressure reduction and changes in flow direction inside the intake screens may lead to the formation of vortices in the suction pipes. Only a few researchers have conducted numerical simulations in order to solve the flow field and determine the flow pattern within and around the screen [20-24]. Unlike the previous researchers that have obtained results from the studies carried out on the friction factor and the pressure drop in the screen, the present study in a different manner surveys the vortex formation, flow patterns and flow uniformity inside a metal screen of the water intake system of a pumping station under tidal conditions. Zhan et. al. numerically investigated the flow pattern in multiple pump intake systems [25]. In comparison with the results presented by Zhan et. al., in this study the flow pattern in the intake system is more complex due to the intake screen mounted on the suction pipe.

To investigate the vortex formation in water intake system of the Bavi pumping station, the work started by obtaining the governing equations for two-phase (water-air) steady flow. An adopted TSJ test model and experimental measurements validates computational fluid dynamic (CFD) results of this study. Experimental measurements include water elevations and free surface velocity of the River in a 1-year period. A detailed geometrical model of the water intake system is constructed and numerical flow simulations are obtained for various River conditions to determine vortex position and structure.

\section{Governing equations and numerical algorithms}

In the present work, the RANS equations together with the Realizable $k-\varepsilon$ turbulence model are used to obtain the main parameters of the flow field. In order to determine the flow patterns more accurately, viscosity is considered [4]. VOF model is employed to capture the free surface. Generally, the nature of the vortex formation is unsteady. The steady state solution of the flow field show the mean features of the formed vortices in the water intake system [26]. Since the aim of this study is to determine the vortex formation in the water intake system to improve the design of the Bavi pumping station, steady state simulations are adequate for this study.

\subsection{RANS equations}

The velocity components of turbulent flow can be written as $u_{i}=\bar{u}_{i}+u_{i}^{\prime}$ in which $\bar{u}_{i}$ is the mean value and $u_{i}^{\prime}$ is the fluctuation value of the velocity components $(i=1,2,3)$. In a similar way, the pressure components of the flow is given by $P=\bar{P}+P^{\prime}$. The continuity and momentum equations respectively described by Eqs. 1 and 2 in Cartesian coordinates.

$\frac{\partial}{\partial x_{i}}\left(\rho \overline{u_{i}}\right)=0$

$\frac{\partial}{\partial x_{j}}\left(\rho \bar{u}_{i} \bar{u}_{j}\right)=-\frac{\partial \bar{P}}{\partial x_{i}}+\rho g_{i}+\frac{\partial}{\partial x_{j}}\left(\mu \frac{\partial \bar{u}_{i}}{\partial x_{j}}-\rho \overline{u_{i}^{\prime} u_{j}^{\prime}}\right)$

Equations 1 and 2 are known as Reynolds-averaged Navier-Stokes (RANS) equations in which $\rho$ is the fluid density, $g_{i}$ is the ith component of the gravitational acceleration and $\mu$ is the viscosity. In Eq. $2, \rho \overline{u_{i}^{\prime} u_{j}^{\prime}}$ is the Reynolds shear stress, which introduces additional unknowns to the set of equations. A proper mathematical model must replace the Reynolds shear stress to close the set of equations. The Reynolds-averaged Navier-Stokes (RANS) equations are transport equations for the mean fluid variables in a turbulent flow. To solve the RANS equations, Reynolds shear stress must be expressed in terms of other quantities related to the mean velocity [27]. According to the Boussinesq's formula, Eq. 3 expresses the Reynolds shear stress.

$\rho \overline{u_{i}^{\prime} u_{j}^{\prime}}=\mu_{t}\left(\frac{\partial u_{i}}{\partial x_{j}}+\frac{\partial u_{j}}{\partial x_{i}}\right)-\frac{2}{3} \rho k \delta_{i j}$

In Eq. $3, \mu_{t}$ is the turbulence viscosity, $\delta$ is the Kronecker symbol and $k$ is the turbulence kinetic energy. Equation 4, [28], defines the turbulence viscosity.

$\mu_{t}=C_{\mu} \rho \frac{k^{2}}{\varepsilon}$

In which $\varepsilon$ is the turbulence dissipation rate and for Realizable $k-\varepsilon$ model, the following relations give definition of $C_{\mu}$ in Eq. 4.

$C_{\mu}=\frac{1}{A_{0}+A_{s} U^{* k / \varepsilon}}, \quad A_{0}=4.0, \quad A_{s}=\sqrt{6} \cos \phi, \quad \phi=\frac{1}{3} \cos ^{-1}(\sqrt{6} W)$

$W=\frac{S_{i j} S_{j k} S_{k i}}{\left(S_{i j} S_{i j}\right)^{3 / 2}}, \quad U^{*}=\sqrt{S_{i j} S_{i j}+\tilde{\Omega}_{i j} \tilde{\Omega}_{i j}}, \quad \tilde{\Omega}_{i j}=\Omega_{i j}-2 \varepsilon_{i j k} \omega_{k}, \quad \Omega_{i j}=\bar{\Omega}_{i j}-\varepsilon_{i j k} \omega_{k}$ 


\subsection{Turbulence model}

In order to properly model the Reynolds stresses, the quantities of $k$ and $\varepsilon$ should be determined. The Realizable $k-\varepsilon$ model uses a modified transport equation for turbulence dissipation rate $\varepsilon$, which enhances the numerical stability in turbulent flow calculations in comparison with the standard $k-\varepsilon$ model. In steady state condition, Realizable $k-\varepsilon$ model uses the following equations for $k$ and $\varepsilon$ (Eqs. 5 and 6) [29]:

$$
\begin{aligned}
& \frac{\partial}{\partial x_{j}}\left(\rho k u_{j}\right)=\frac{\partial}{\partial x_{j}}\left[\left(\mu+\frac{\mu_{t}}{\sigma_{k}}\right) \frac{\partial k}{\partial x_{j}}\right]+G_{k}-\rho \varepsilon+S_{k} \\
& \frac{\partial}{\partial x_{j}}\left(\rho \varepsilon u_{j}\right)=\frac{\partial}{\partial x_{j}}\left[\left(\mu+\frac{\mu_{t}}{\sigma_{\varepsilon}}\right) \frac{\partial \varepsilon}{\partial x_{j}}\right]+\rho C_{1} S \varepsilon-\rho C_{2} \frac{\varepsilon^{2}}{k+\sqrt{v \varepsilon}}+S_{\varepsilon}
\end{aligned}
$$

where, $G_{k}$ is the generation of turbulence kinetic energy due to the mean velocity gradients. According to the Boussinesq's approximation $G_{k}=\mu_{t} S^{2}$ in which $S$ is the mean rate modulus of the strain tensor. In above equations $C_{1}=\max \left[0.43, \frac{\eta}{\eta+5}\right]$ in which $\eta=S \frac{k}{\varepsilon}$ and $S=\sqrt{2 S_{i j} S_{i j}}$ where, $S_{i j}=\frac{1}{2}\left(\frac{\partial u_{j}}{\partial x_{i}}+\frac{\partial u_{i}}{\partial x_{j}}\right)$.

In Eqs. 5 and $6, \sigma_{k}$ and $\sigma_{\varepsilon}$ are turbulence Prandtl number for $k$ and $\varepsilon$ respectively. $S_{\varepsilon}$ and $S_{k}$ are the source terms and $C_{2}$ is constant. In Eqs. 5 and 6, $C_{2}=1.9, \sigma_{k}=1, \sigma_{\varepsilon}=1.2$ and there are no source terms in the flow.

\subsection{VOF model}

In this study, two-phase (water-air) flow is considered. The VOF method is used for capturing interface between air and water at the free surface of water. In this method, to solve the continuity and momentum equations, the volume fractions of the phases are used. Equations 7 and 8 define the volume fraction. $\vec{u} \cdot \nabla \alpha_{q}=0$

$\sum \alpha_{q}=1, q=1,2$

For determining the flow parameters, a single momentum equation is solved as defined in Eq. 2. The momentum equation is dependent on the volume fraction through the properties $\rho$ and $\mu$ as given in Eqs. 9 and 10 .

$\rho=\sum \alpha_{q} \rho_{q}$

$\mu=\sum \alpha_{q} \mu_{q}$

\subsection{Numerical algorithms}

The momentum and turbulence equations are discretized by Quadratic Upstream Interpolation for Convective Kinematics (QUICK) method. Pressure Staggering Option (PRESTO) discretization scheme is used and the pressure-velocity coupling algorithm is set to SIMPLE. High Resolution Interface Capturing (Modified HRIC) scheme is employed for the VOF model [30]. The residuals of the velocity components, pressure and turbulence quantities for numerical calculations are in order of $1 \times 10^{-6}$ and this value for volume fraction is in order of $1 \times 10^{-12}$. These values are sufficient to regard the solutions as convergent. The simulations are conducted with the commercial CFD code ANSYS-FLUENT [31].

\section{Validation of present CFD analysis method}

In order to acquire the reliability of CFD analysis method employed in this study, benchmarking simulation test is performed. Turbo machinery Society of Japan (TSJ)
Fig. 1 Benchmarking pump intake model used for CFD analysis [11]

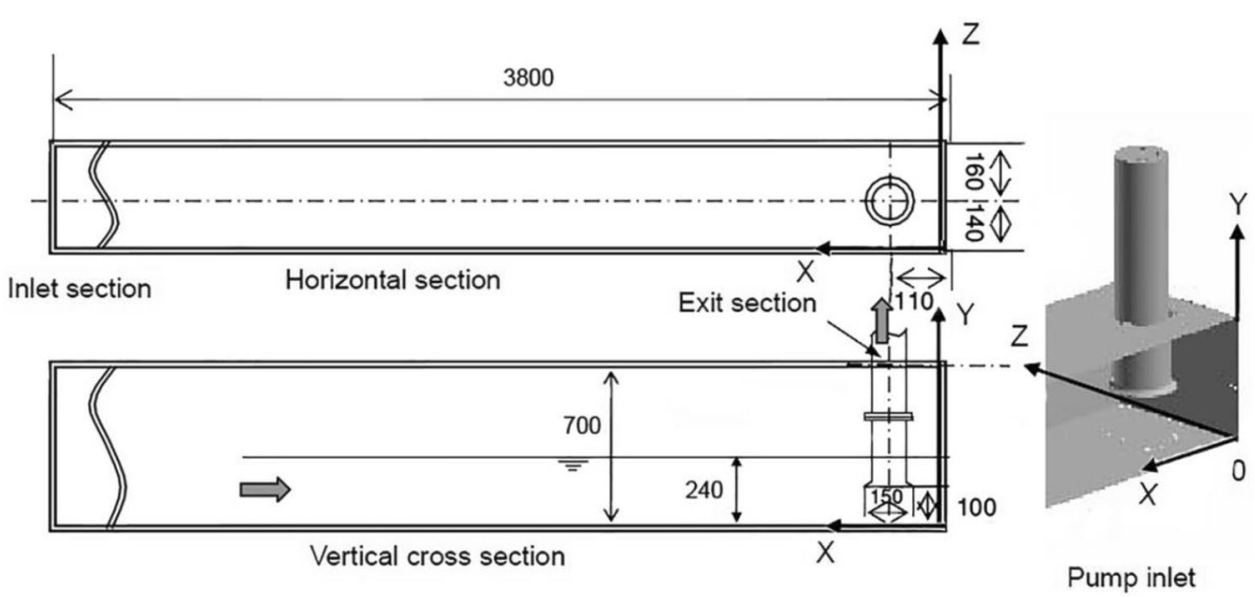


introduced the benchmarking pump intake model used here. Figure 1 shows the TSJ pump intake model for benchmarking simulation test.

The values of $\mathrm{Y}$-velocity $\left(\mathrm{V}_{\mathrm{Y}}\right)$ and Z-velocity $\left(\mathrm{V}_{\mathrm{Z}}\right)$ on a plane parallel to the $X Z$ plane and close to the pump bell $(Y=85 \mathrm{~mm})$ are compared respectively with the TSJ model results and experimental data.

As shown in Fig. 2 the velocity distributions in $\mathrm{Y}$ and $Z$ direction determined by the present CFD analysis method agree well with the experimental data as well as the numerical model test result. However, in comparison with the experimental data there are some differences in Z-velocity distribution, which are due to the accuracy of the experimental method.

\section{Measurement of the free surface elevation and velocity}

The Bavi pumping station locates in Khuzestan province of Iran. The station is constructed at one bank of the Bahmanshir River. There are four pumping units installed in the station. The design static head and discharge of each pump are $27 \mathrm{~m}$ and $1290 \mathrm{~m}^{3} / \mathrm{h}$ respectively. The water intake system is installed directly in the river. The distance between the pipe intake and the bottom of the river is $1.7 \mathrm{~m}$. The river flows into the Persian Gulf, which affects the water elevation of the river as much as about $3 \mathrm{~m}$ due to the low and high tides. When the pipe intake submergence drops below a critical value, air core vortices enter the suction pipe and cause air entrainment into the pump. Ingress of air into the pump casing causes noisy operation and severe vibration, which in turn increases the cost of maintenance and repair. Therefore, the measurement of

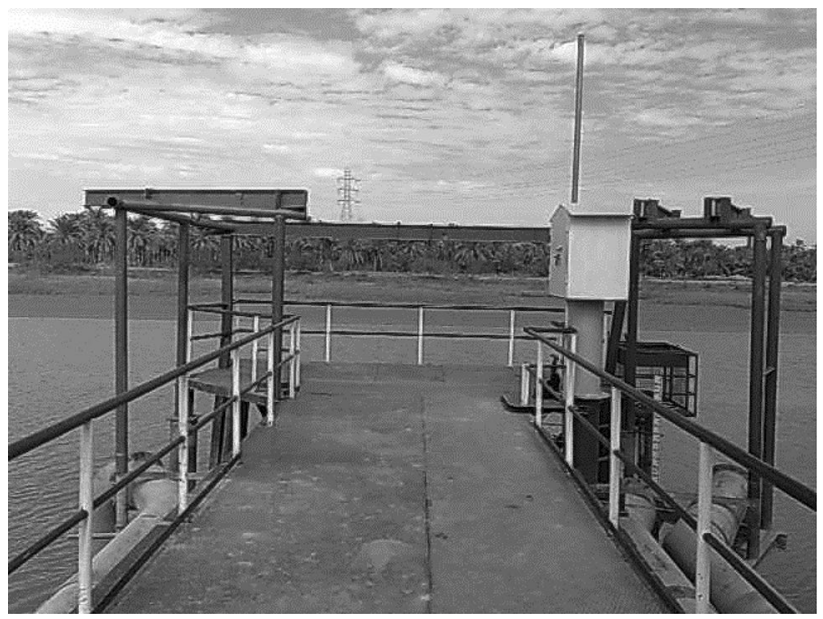

Fig. 3 Suction pipes of the Bavi pumping station

the free surface elevation is important to analyze the performance of the pumps during tides. A view of the suction pipes of the Bavi pumping station is shown in Fig. 3.

A gauge was used to measure the elevation of the Bahmanshir River in a 1-year period. The gauge is installed close to the suction pipe. By plotting a graph of the measurements against month, a periodic diagram is obtained as shown in Fig. 4. In order to plot the graph, maximum and minimum data from each day of the year are used to show the changes of the free surface elevation appropriately (Fig. 4).

According to the measurements, the lowest low tide is $2.1 \mathrm{~m}$, which occurred on August 4th; and the highest high tide is $4.9 \mathrm{~m}$ which occurred on May 7th. To perform simulations, seven water elevations are considered between the highest high level $(4.9 \mathrm{~m})$ and the lowest

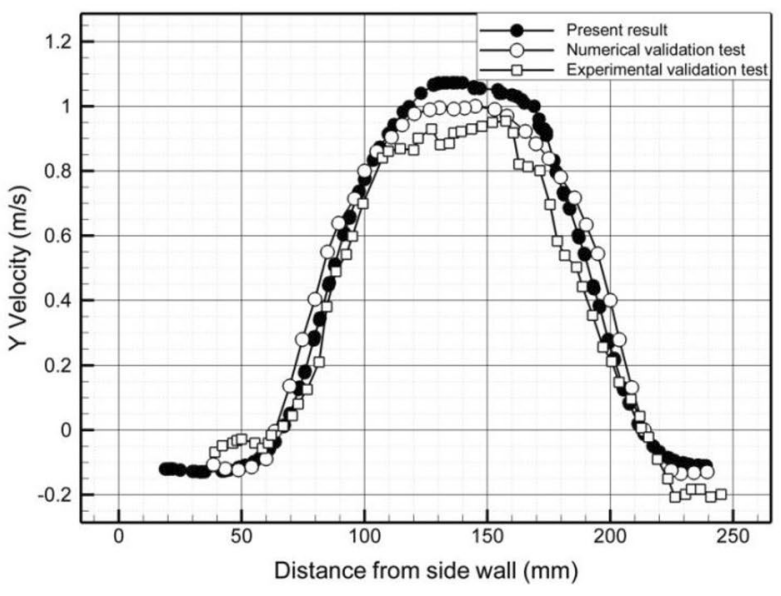

(a) Y-velocity distribution

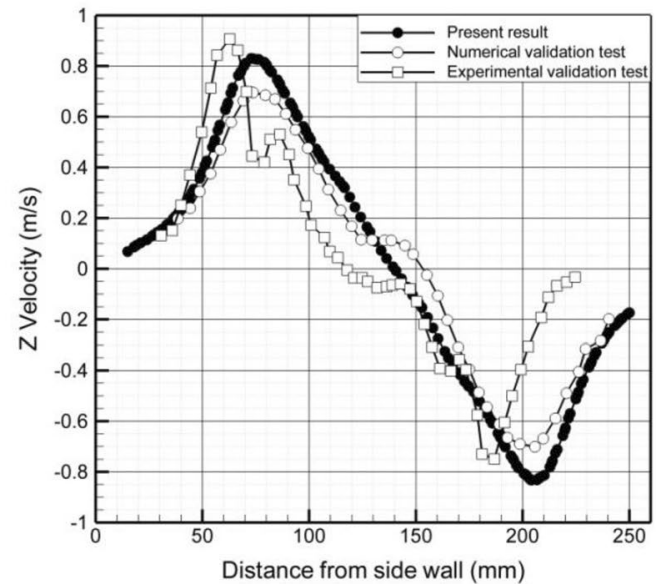

(b) Z-velocity distribution

Fig. 2 Comparison of the present CFD results with the benchmark results. a Y-velocity distribution, $\mathbf{b}$ Z-velocity distribution 
low level $(2.1 \mathrm{~m})$; and the numerical results for each elevation are presented. Numerical simulations are conducted at $2.1 \mathrm{~m}, 2.5 \mathrm{~m}, 3 \mathrm{~m}, 3.5 \mathrm{~m}, 4 \mathrm{~m}, 4.5 \mathrm{~m}$ and $4.9 \mathrm{~m}$ free surface elevations. As the water level decreases, the free surface velocity increases. Therefore, the free surface velocity during a year is also measured and shown in Table 1.

\section{Modeling and grid generation}

In modeling the water intake system of the pumping station, no scaling is used and the dimensions are that of the physical model. The water intake system consisted of a suction pipe and a fine intake screen (with openings of $0.14 \mathrm{~cm}$ ). The intake screen is mounted on the pipe intake to prevent suspended solids and aquatic organisms from entering the water intake system. The actual intake screen is shown in Fig. 5.

\subsection{Geometric model}

In order to conduct the numerical simulation of the flow field, a geometric model is constructed. The computational area includes the suction pipe, the intake screen and a domain around the screen. In Fig. 6, the geometric model of the intake screen (Fig. 6a) and a sectional view (Fig. 6b) are shown.

As seen in Fig. 6b, there is a check valve in the intake screen that prevents air from entering the suction pipe during the starting up period of the pump. The geometric model of the water intake system is shown in Fig. 7.

The diameter of the suction pipe is $49 \mathrm{~cm}$ and the intake screen is mounted in such a way that its distance from the bed of the river is $1 \mathrm{~m}$. To simulate the river stream, a domain is considered around the intake screen.

Table 1 Water elevation measurements and corresponding free surface velocities
The dimensions of the domain ensure that the main characteristics of the river are captured. The computational domain is shown in Fig. 8.

\subsection{Computational grid}

The computational domain is discretized by $9,376,209$ unstructured tetrahedral elements that are shown in Fig. 9.

Due to the model complexity, the computational domain is divided into different parts and unstructured grid is generated for each part. The computational grid of the intake screen is shown in Fig. 10.

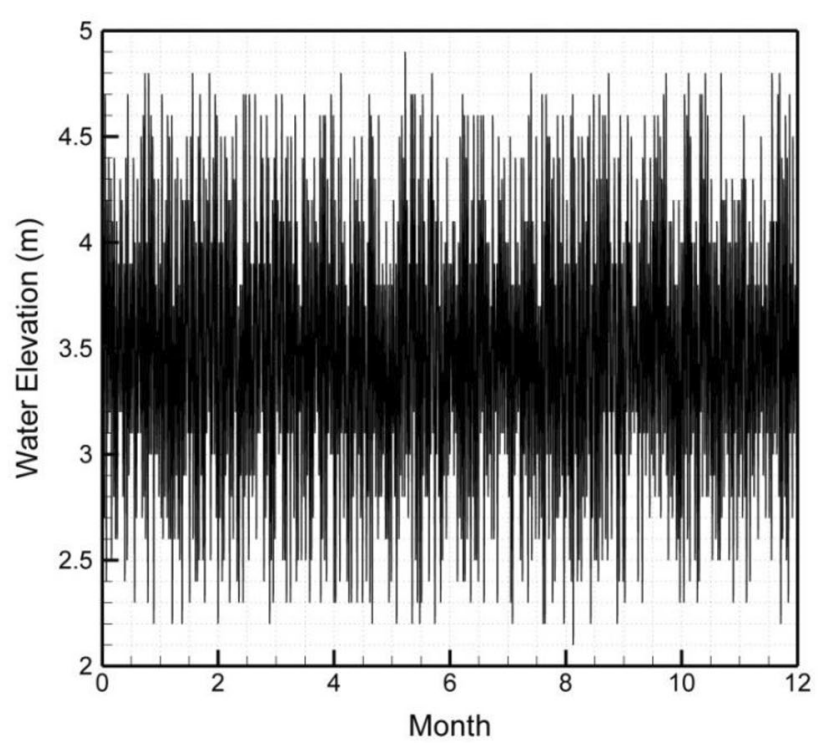

Fig. 4 Bahmanshir River water level during low and high tides in a 1-year period

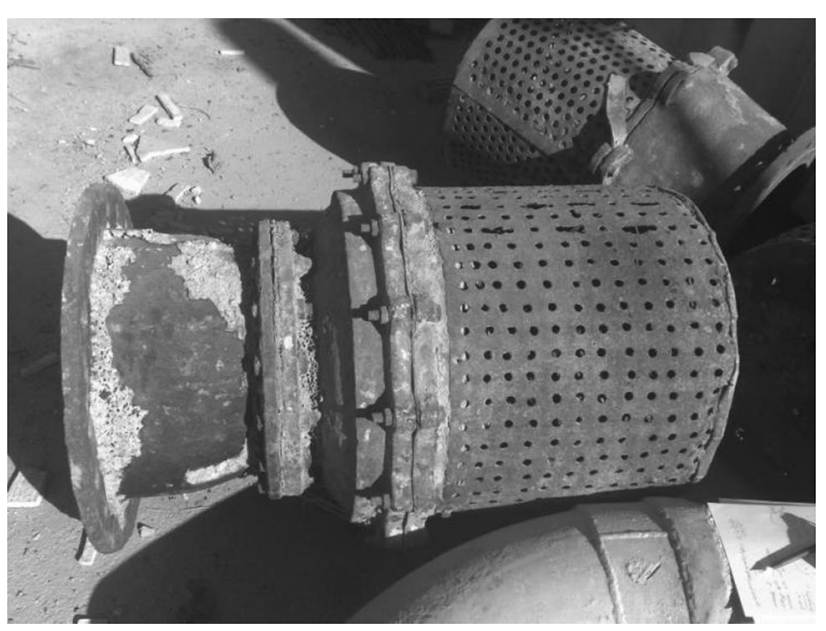

Fig. 5 Photograph of the intake screen

\begin{tabular}{ll}
\hline $\begin{array}{l}\text { Water eleva- } \\
\text { tion }(\mathrm{m})\end{array}$ & $\begin{array}{l}\text { Free surface } \\
\text { velocity }(\mathrm{m} / \mathrm{s})\end{array}$ \\
\hline 4.9 & 1.05 \\
4.5 & 1.15 \\
4.4 & 1.21 \\
4.2 & 1.35 \\
4.1 & 1.4 \\
4 & 1.55 \\
3.5 & 1.6 \\
3 & 2.05 \\
2.5 & 2.1 \\
2.1 & 2.35 \\
\hline
\end{tabular}


Fig. 6 a Geometric model of the intake screen; $\mathbf{b}$ sectional view

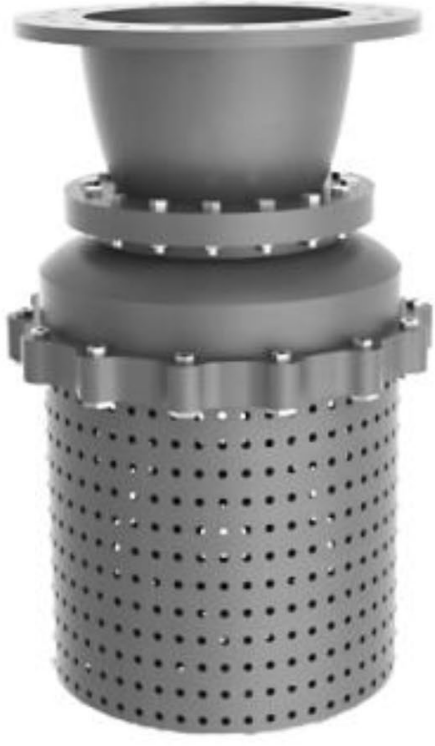

(a)

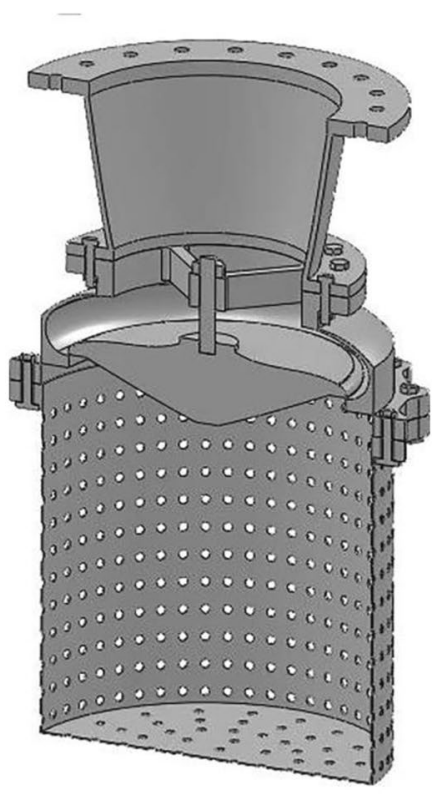

(b)
Fig. 7 Geometric model of the water intake system
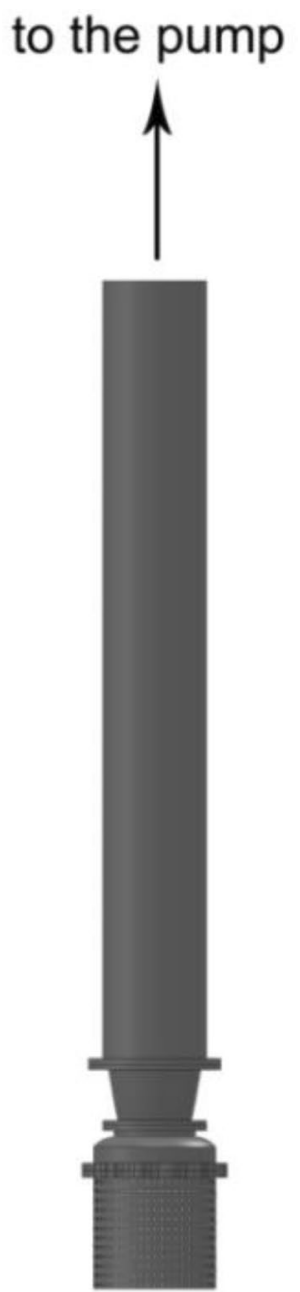

Figure $11 \mathrm{a}$ and $\mathrm{b}$ respectively show the left and bottom view of the grid generation around the openings.

Sectional views of the computational grid around the intake screen and the suction pipe are shown in Fig. 12a and $b$.

\subsection{Boundary conditions}

The stream wise dimension of the computational domain is extended to ensure that the flow is fully developed and that there exists uniform river flow (see Fig. 8). The river flow is assumed as fully developed turbulent flow in open channels. Uniform flow is assumed thorough the river domain [32]. Non-uniform approaching velocity would cause high flow non-uniformity and vortex formation on the suction side of the pump [12]. Because the real boundaries of the river extend farther than the assumed domain, the side boundaries are assumed to be symmetrical plane to ensure that there is no flow normal to the sidewalls. No-slip condition is employed at the river bed and to the walls of the pipe and the intake screen. Constant pressure boundary condition of to $1 \mathrm{~atm}$ is applied to the free surface. Zero pressure gradients are applied to the inlet and outlet boundaries of the river. The discharge of the pump is $1290 \mathrm{~m}^{3} / \mathrm{h}$ and it is assumed that the pump is working under constant flow rate, so constant flow boundary condition at the outlet of the suction pipe is used. 
Fig. 8 Computational domain

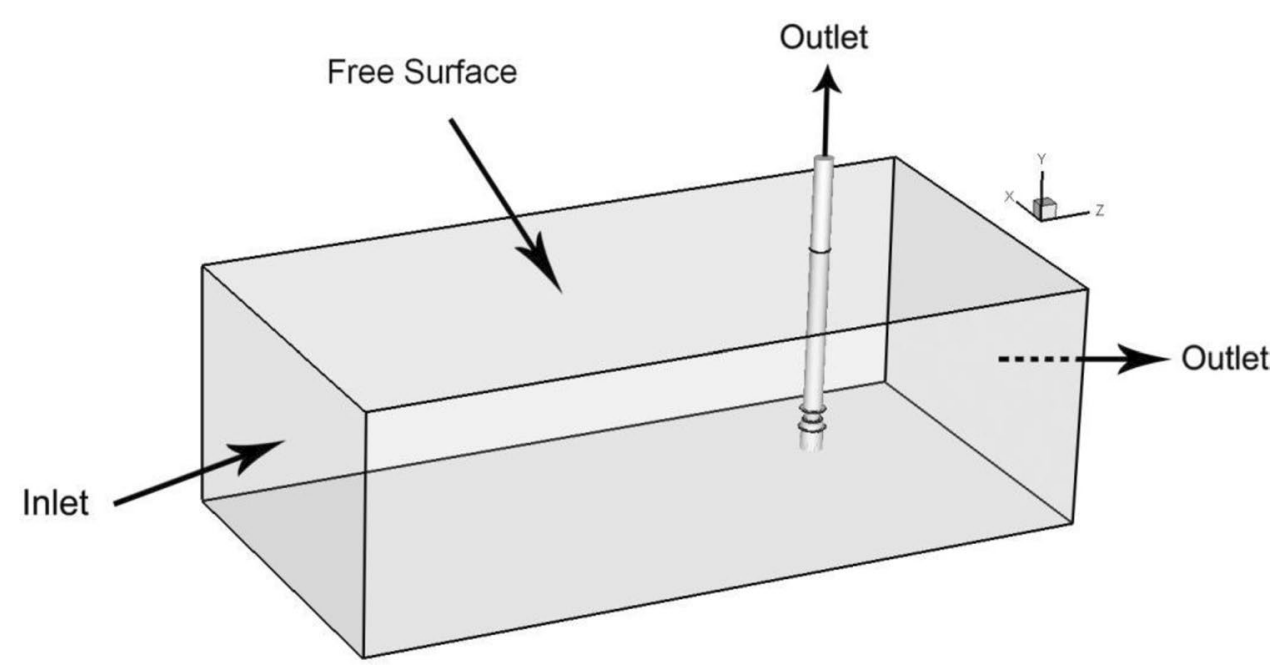

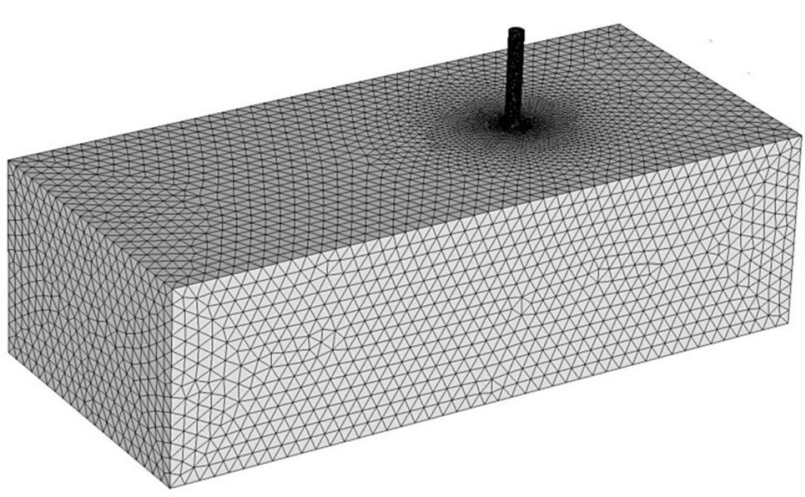

Fig. 9 Computational grid of the whole domain

\subsection{Grid study}

Simulation results are highly dependent on grid generation accuracy [33]. A grid study is carried out to minimize the grid size effect on simulation results. Simulations at $2.1 \mathrm{~m}$ and $4.9 \mathrm{~m}$ free surface elevations are performed for various grid densities and the results (including maximum axial velocity at the pipe intake) are compared and summarized in Tables 2 and 3.

\section{Results and discussions}

\subsection{Streamlines and vortex cores}

In order to recognize the vortices that are stretched to the suction pipe, the iso-surfaces of the vortex strength are shown in Fig. 13. It should be noted that the vortices

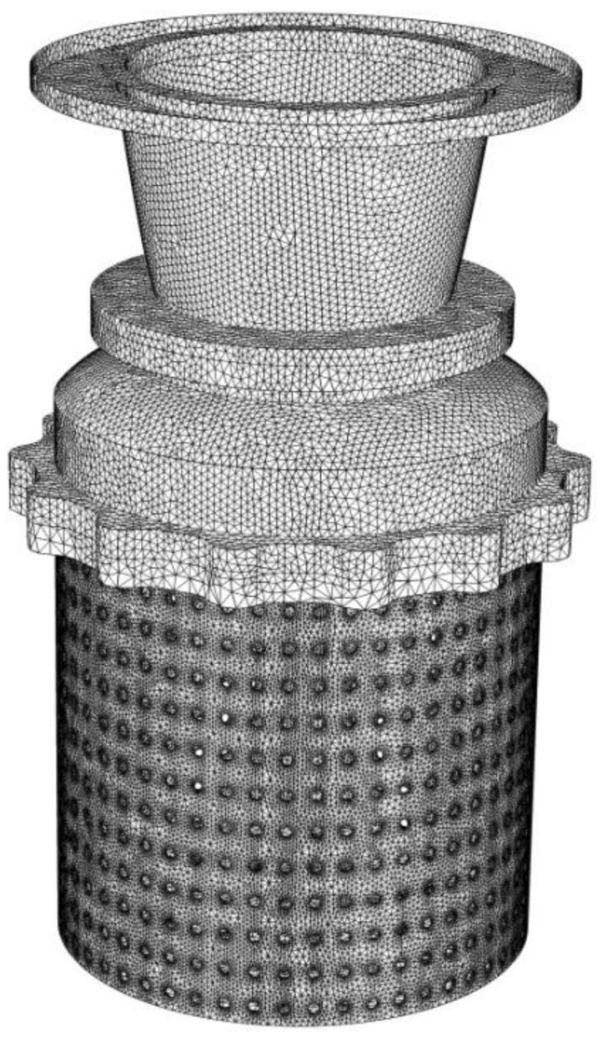

Fig. 10 Computational grid of the intake screen

in the flow are unstable so the steady state formulation shows the mean features of the vortex cores.

According to Fig. 13 as water level varies from 2.1 to $4.9 \mathrm{~m}$, two wall-attached vortices permanently are stretched to the intake screen. These vortices are attached to the wall of the suction pipe. When the vortices reach the pump impeller, they apply uneven 


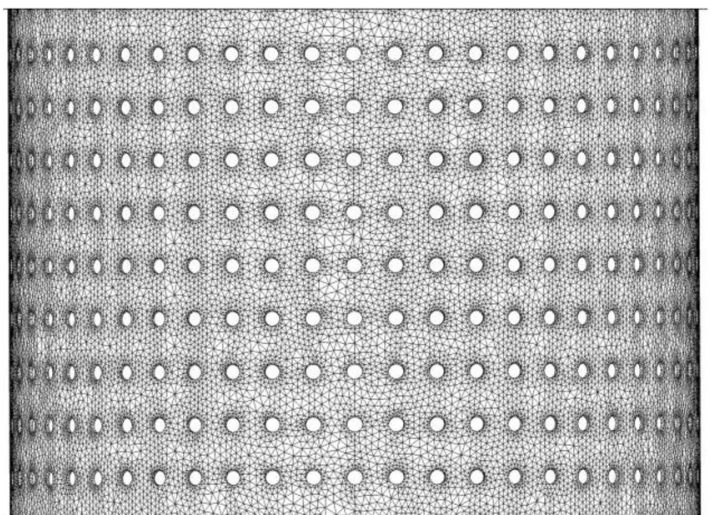

(a)

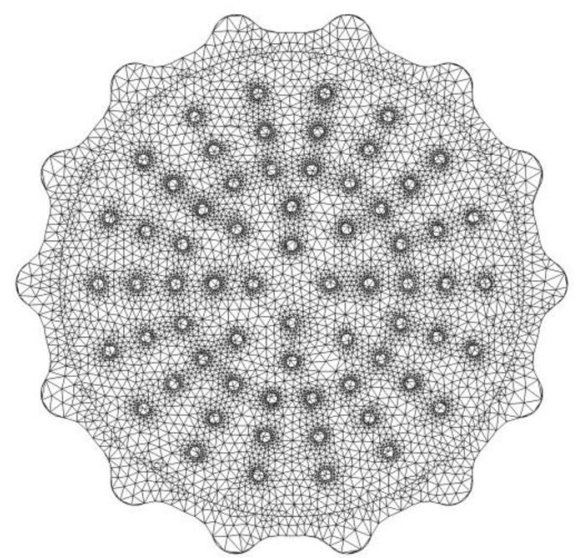

(b)

Fig. 11 Computational grid around the screen openings $\mathbf{a}$ left view; b bottom view

Table 2 Comparison of maximum axial velocity for various grid densities (at $2.1 \mathrm{~m}$ free surface elevation)

\begin{tabular}{llll}
\hline Step & $\begin{array}{l}\text { Computational } \\
\text { grid elements }\end{array}$ & $\begin{array}{l}\text { Maximum axial } \\
\text { velocity }(\mathrm{m} / \mathrm{s})\end{array}$ & $\begin{array}{l}\text { Relative change from } \\
\text { the previous grid (\%) }\end{array}$ \\
\hline 1 & $4,305,522$ & 9.3 & - \\
2 & $7,447,236$ & 9.7 & $4.3 \%$ \\
3 & $9,376,209$ & 9.8 & $1 \%$ \\
\hline
\end{tabular}

Table 3 Comparison of maximum axial velocity for various grid densities (at $4.9 \mathrm{~m}$ free surface elevation)

\begin{tabular}{llll}
\hline Step & $\begin{array}{l}\text { Computational } \\
\text { grid elements }\end{array}$ & $\begin{array}{l}\text { Maximum axial } \\
\text { velocity }(\mathrm{m} / \mathrm{s})\end{array}$ & $\begin{array}{l}\text { Relative change from } \\
\text { the previous grid }(\%)\end{array}$ \\
\hline 1 & $4,305,522$ & 9.2 & - \\
2 & $7,447,236$ & 9.53 & 3.6 \\
3 & $9,376,209$ & 9.6 & 0.7 \\
\hline
\end{tabular}

pressure. Uneven pressure distribution on the surface of the impeller causes high vibration and noise in the pump. In extreme cases, vibration will damage the pump bearings.

In addition, the numerical results show that in all cases two large vortices exist in the intake screen; these vortices are shown in Fig. 14 at $2.1 \mathrm{~m}$ and $4.9 \mathrm{~m}$ free surface elevations.

The streamlines inside the intake screen at elevations $2.1 \mathrm{~m}$ and $4.9 \mathrm{~m}$ are shown respectively in Fig. 15a and b. Numerical simulation predicts that two vortices formed in the intake screen are symmetrical but with some differences in strength (Fig. 16a and b).
Figure 16 shows that as the water elevation of the river decreases, the tangential velocity and the circulation of the vortices in the screen increases. It shows that insufficient submergence of the pipe intake causes the formation of stronger vortices in the water intake system. Also from Fig. 16 it can be seen that the left vortex (LV) has a higher intensity than the right (RV) one. The difference in the strength of the vortices is related to uneven distribution of vorticity which in turn is due to the non-uniformity of the flow when it passes through the screen. Figure 17 shows the magnitude of axial velocity at the pipe intake at $2.1 \mathrm{~m}$ and $4.9 \mathrm{~m}$ free surface elevations. As shown, the distribution is to-some-extent symmetrical and at the center, the axial velocity reaches the maximum value. Due to the vortex formation near the wall of the suction pipe, the axial velocities have negative values. Negative velocity values show reverse directions of flow in this area. It is also obvious in Fig. 17 during high and low tides, the changes in magnitude of axial velocity at the pipe intake are negligible. The reason is that the volume flow rate at the outlet boundary is assumed constant as discussed in Sect. 5.3. Therefore, the velocity magnitudes at the pipe intake during high and low tides would not change considerably.

In Fig. 18, the streamlines at $2.1 \mathrm{~m}$ free surface elevation in Z-plane are shown. There is no backflow at the outlet boundaries. Two vortices are formed at the pipe intake near the wall of the pipe. At various free surface elevations the same streamlines are obtained; the reason is that the velocity distributions inside the suction pipe at various elevations are the same as discussed previously (Fig. 17). 
Fig. 12 a A cross-section in computational grid; $\mathbf{b}$ close view

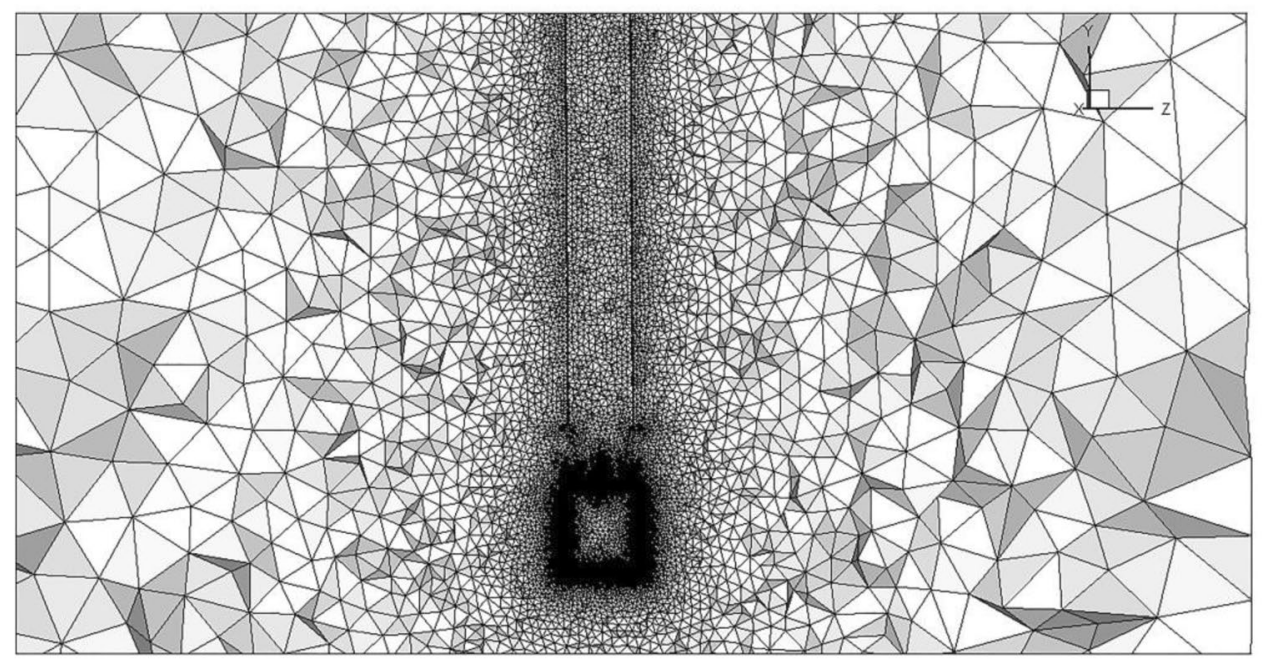

(a)

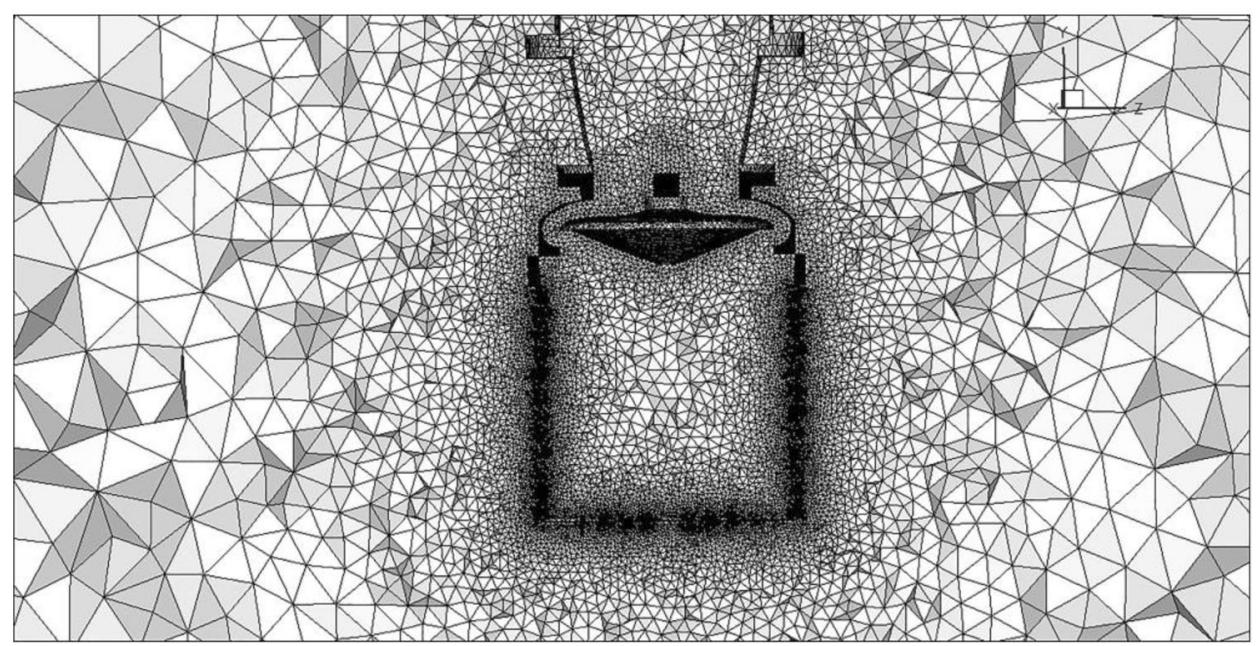

(b)

\subsection{Flow uniformity}

The uniformity of the flow field parameters, such as velocity and pressure, has a direct influence on the pump efficiency. As discussed, Figs. 17 and 18 show non-uniform distribution of the axial flow at the pipe intake. In the present work, the uniformity of velocity at the pipe intake is investigated. The velocity uniformity based on axial velocity is defined by Eq. 11. The flow uniformity is denoted by $\eta$. As $\eta$ approaches to $100 \%$, it shows more uniform flow [34].
$\eta=\left[1-\frac{1}{\bar{V}_{y}} \sqrt{\frac{\sum_{i=1}^{n}\left(V_{y i}-\bar{V}_{y}\right)^{2}}{n}}\right] \times 100 \%$

In Eq. $11, \bar{V}_{y}$ is the mass-weighted average axial velocity, $V_{y i}$ is axial velocity in grid element, and $n$ is the number of elements in considered cross-section. Mass-weighted average axial velocity $\left(\bar{V}_{y}\right)$ in Eq. 11 , can be obtained from Eq. 12:

$\bar{V}_{y}=\frac{\sum_{i=1}^{n} V_{y i} \rho\left|V_{y i} d A_{i}\right|}{\sum_{i=1}^{n} \rho\left|V_{y i} d A_{i}\right|}$ 


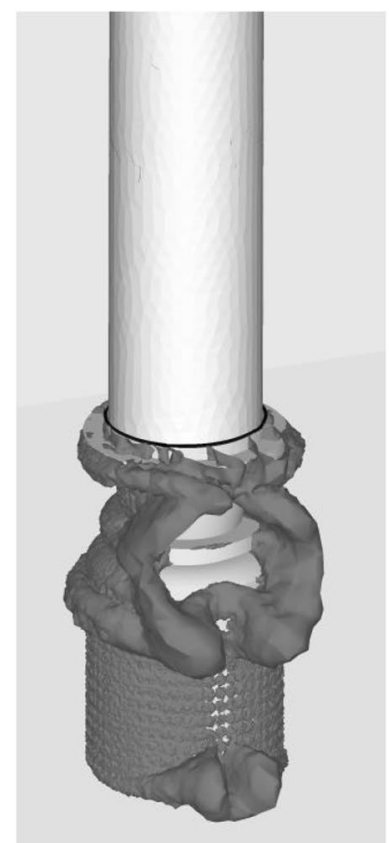

(a)

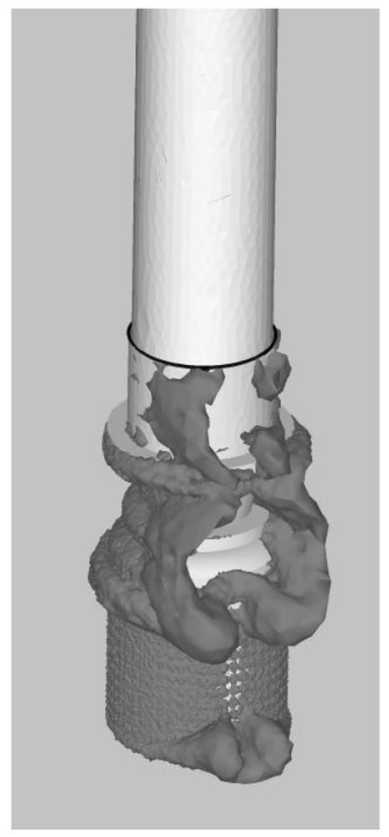

(b)

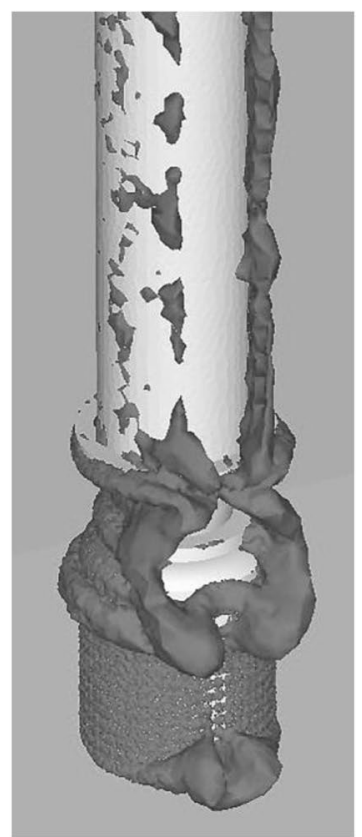

(c)

Fig. 13 Vortex structure by the iso-surface of vorticity magnitude at elevations. a 2.1 m; b 2.5 m; c 4.9 m

Fig. 14 Vortex cores in the intake screen at free surface elevations. a $2.1 \mathrm{~m} ;$ b $4.9 \mathrm{~m}$

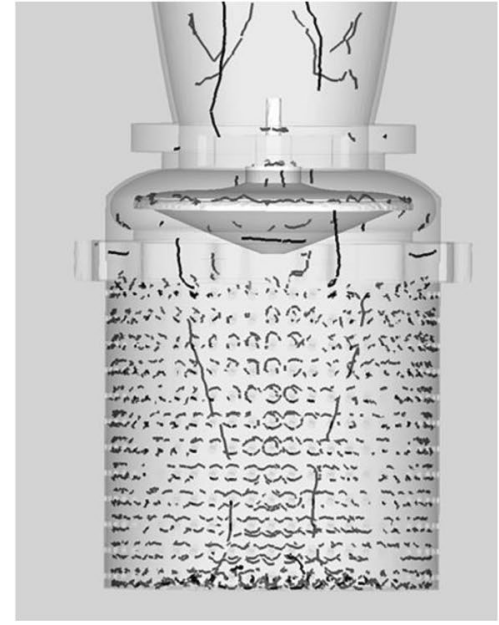

(a)

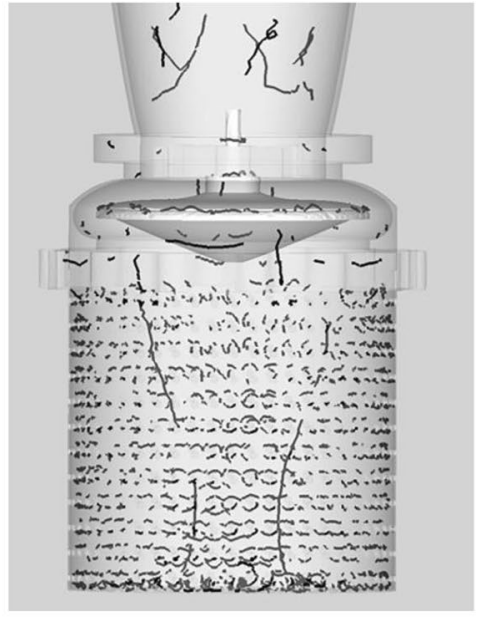

(b) where $d A_{i}$ is the corresponding area of the grid element and $\rho$ is the fluid density. Using Eq. 11 at $2.1 \mathrm{~m}$ free surface elevation, the calculated flow uniformity in a cross-sectional plane at the pipe intake is $20.3 \%$ while the standard amount of the uniformity should be $90 \%$ or more. This shows low level of uniformity in the suction pipe. As previously discussed, the distributions of the velocity magnitude at the pipe intake at all water levels are the same (Fig. 17). So the calculated flow uniformity is obtained for each elevation. Low level of uniformity is attributed to the existence of the intake screen and its check valve, which facilitate the vortex formation at the pipe intake. More uniform flow distribution on the suction side of the pump will cause the pump to work more efficiently [34]. As a result, the efficiency of the pump is substantially reduced due to the high level of non-uniformity of the flow during tides in the Bavi pumping station. 
Fig. 15 Streamlines in a crosssection of the intake screen at free surface elevations ( $L V$ left vortex, $R V$ right vortex). a $2.1 \mathrm{~m} ; \mathbf{b} 4.9 \mathrm{~m}$

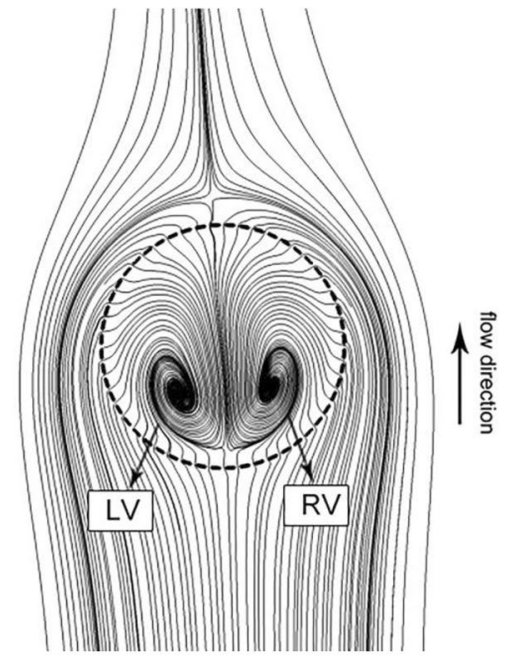

(a)

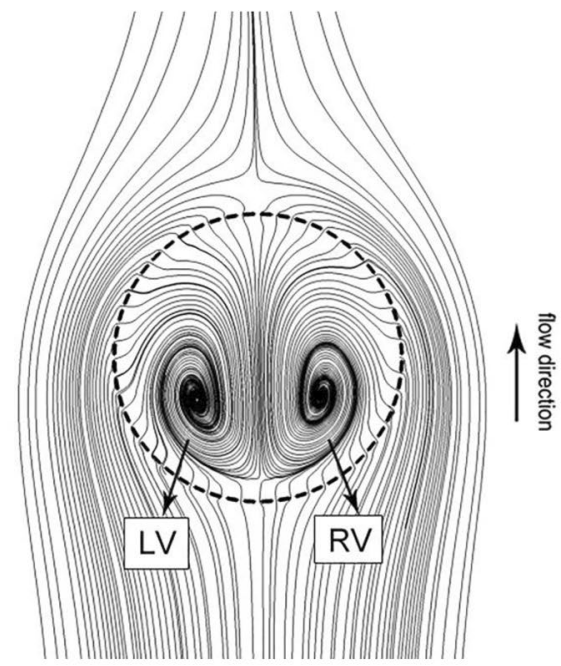

(b)

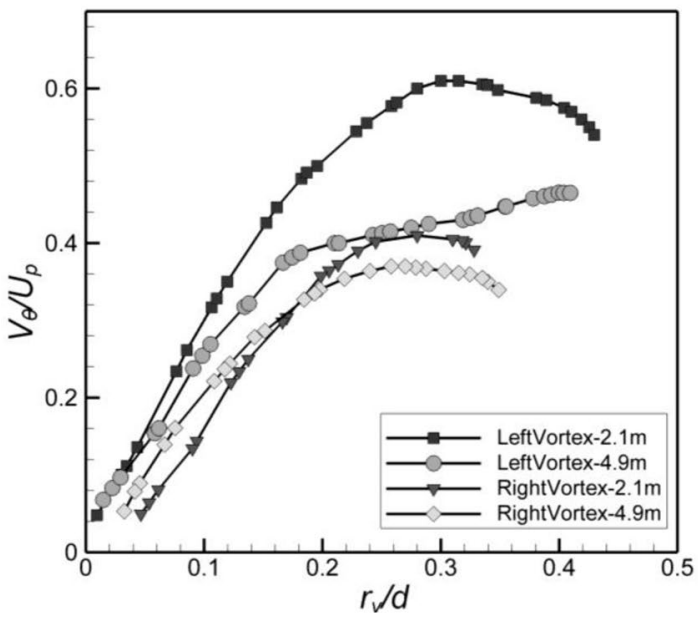

(a)

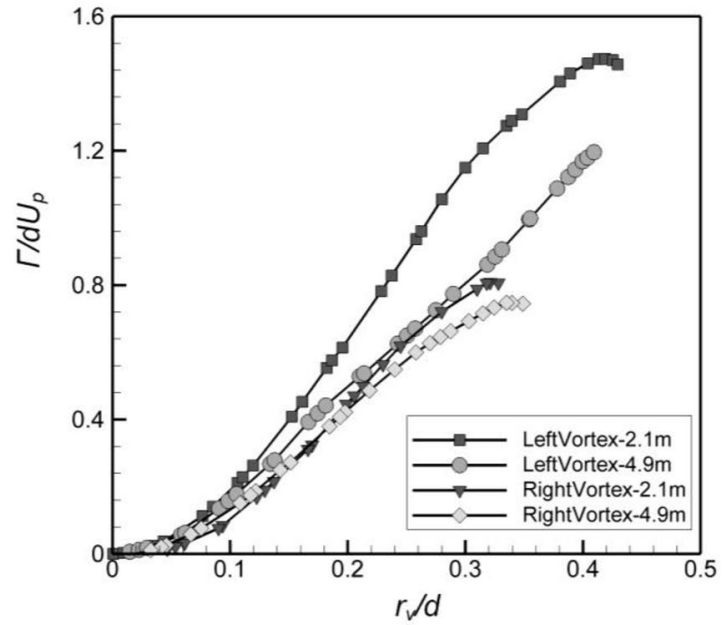

(b)

Fig. 16 Comparison of tangential velocity and circulation of the vortices in the screen. a Tangential velocity; b Circulation

\section{Conclusions}

Pump performance and efficiency in pumping stations constructed near tidal rivers are greatly influenced by tidal variations. This paper presents numerical and experimental investigation of vortex formation in water intake system of a pumping station with varying tidal flows. A detailed threedimensional geometrical model of the intake system is constructed and placed inside a domain representing the river. The geometrical model and the surrounding space are then decomposed using unstructured tetrahedral cells. Numerical simulations of the water intake system are then conducted using Realizable $\mathrm{k}-\varepsilon$ turbulence model. It is shown that the numerical results (including velocity magnitudes) are comparable with TSJ model test and experimental data.

Vortex formation in pipe intake system can greatly affect pump performance. Realizable $\mathrm{k}-\varepsilon$ turbulence model together with VOF two-phase (water-air) model is employed to investigate the vortex formation in the water intake system of the Bavi pumping station. The water intake system consists of a suction pipe and a fine intake screen (with openings of $0.14 \mathrm{~cm}$ ) mounted at the pipe intake. Because of high and low tides, water levels and corresponding free surface velocities are measured in a 1-year period. The water level varies from 2.1 to $4.9 \mathrm{~m}$. During the tides, free surface velocity varies from 


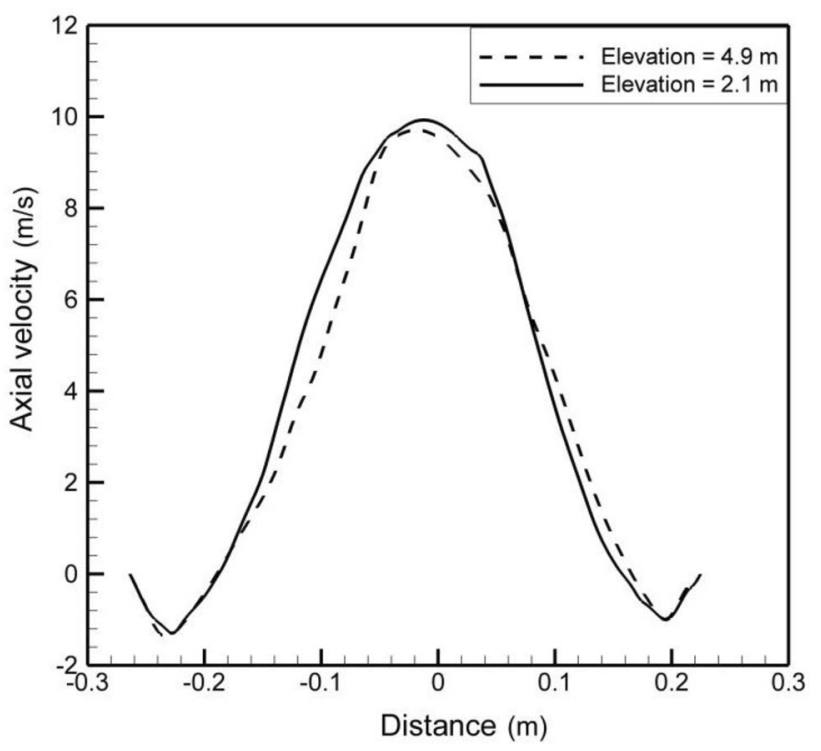

Fig. 17 Distribution of axial velocity magnitude at the pipe intake (at $2.1 \mathrm{~m}$ and $4.9 \mathrm{~m}$ free surface elevations)

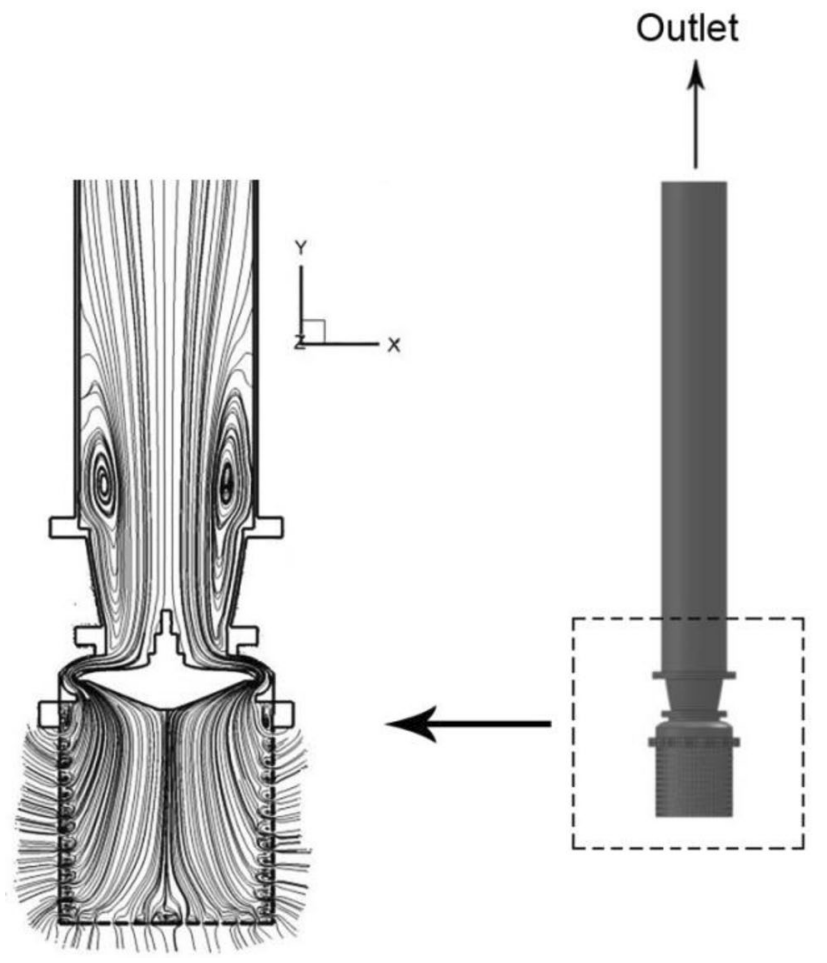

Fig. 18 Streamlines in Z-plane

2.35 to $1.05 \mathrm{~m} / \mathrm{s}$. To perform simulations, seven water elevations are considered between the highest high level $(4.9 \mathrm{~m})$ and the lowest low level $(2.1 \mathrm{~m})$ and the numerical results are presented at $2.1 \mathrm{~m}, 2.5 \mathrm{~m}, 3 \mathrm{~m}, 3.5 \mathrm{~m}, 4 \mathrm{~m}, 4.5 \mathrm{~m}$ and $4.9 \mathrm{~m}$ water elevations.

The numerical results reveal that at all water elevations two wall-attached vortices exist and stretched into the water intake system. Once the vortices reach the pump, they apply uneven pressure to the surface of the impellers. Furthermore, the results show that two symmetrical vortices with different intensities permanently formed in the intake screen. As the pipe intake submergence decreases during low tides, stronger vortices form in the water intake system.

There are also large vortices at the pipe intake that introduce substantial flow non-uniformity on the suction side of the pump. Non-uniform flow reduces the pump efficiency. Low level of flow uniformity is attributed to the existence of the intake screen. The check valve in the intake screen causes asymmetries in the flow field and facilitates the vortex formation. It is recommended, to obtain a more precise numerical solution, future investigations should focus on flow unsteadiness such as non-uniform approaching flow and free surface waves.

Based on the present analysis, to optimize the design of the Bavi pumping station, the following recommendations are given:

(1) Construct a separate suction pool that is not directly connected to the river to avoid the effects of the tidal currents on the intake flow, which facilitate the formation of vortices in the water intake system.

(2) Since the results show vortex formation in the intake screen, multi-stage mesh screen installation at the inlet of the suction pool can replace the intake screen at the pipe intake.

Authors' contributions All authors contributed to the study conception and design. Material preparation, data collection and analysis are performed by Seyed Saied Bahrainian, Mahdi Mahmoudi Sabouki, and Morteza Behbahani-Nejad. The first draft of the manuscript is written by Seyed Saied Bahrainian and all authors commented on previous versions of the manuscript. All authors read and approved the final manuscript.

Availability of data and material The authors have full control of all primary data and they agree to allow the journal to review their data if requested.

Code availability The associated data sets of the software application generated during the current study are available from the corresponding author.

\section{Compliance with ethical standards}

Conflicts of interest The authors declare that they have no conflict of interest. 
Open Access This article is licensed under a Creative Commons Attribution 4.0 International License, which permits use, sharing, adaptation, distribution and reproduction in any medium or format, as long as you give appropriate credit to the original author(s) and the source, provide a link to the Creative Commons licence, and indicate if changes were made. The images or other third party material in this article are included in the article's Creative Commons licence, unless indicated otherwise in a credit line to the material. If material is not included in the article's Creative Commons licence and your intended use is not permitted by statutory regulation or exceeds the permitted use, you will need to obtain permission directly from the copyright holder. To view a copy of this licence, visit http://creativecommons.org/licenses/by/4.0/.

\section{References}

1. Constantinescu GS, Patel VC (1998) Numerical model for simulation of pump-intake flow and vortices. J Hydraul Eng 124:123134. https://doi.org/10.1061/(ASCE)0733-9429(1998)124:2(123)

2. Rajendran VP, Constantinescu GS, Patel VC (1999) Experimental validation of numerical model of flow in pump-intake bays. J Hydraul Eng 125:1119-1125. https://doi.org/10.1061/ (ASCE)0733-9429(1999)125:11(1119)

3. Constantinescu GS, Patel VC (2000) Role of turbulence model in prediction of pump-bay vortices. J Hydraul Eng 126:387-391. https://doi.org/10.1061/(ASCE)0733-9429(2000)126:5(387)

4. Wei-Liang C, Shih-Chun H (2011) Three-dimensional numerical simulation of intake model with cross flow. J Hydrodyn 23:314324. https://doi.org/10.1016/S1001-6058(10)60118-7

5. Li S, Lai Y, Weber L, Silva JM, Patel VC (2004) Validation of a threedimensional numerical model for water-pump intakes. J Hydraul Res 42:282-292. https://doi.org/10.1080/00221686.2004.9728393

6. Hong-Xun C, Jia-Hong G (2007) Numerical simulation of 3-d turbulent flow in the multi-intakes sump of the pump station. J Hydrodyn 19:42-47. https://doi.org/10.1016/S1001 -6058(07)60026-2

7. Tang XL, Wang FJ, Li YJ, Cong GH, Shi XY, Wu YL, Qi LY (2011) Numerical investigations of vortex flows and vortex suppression schemes in a large pumping-station. J Mech Eng Sci 225:14591480. https://doi.org/10.1177/2041298310393447

8. Pradeep S, Sayantan G, Prasad PG, Mohan Kumar MS (2012) CFD simulation and experimental validation of a horizontal pump intake system. ISH J Hydraul Eng 18:173-185. https:// doi.org/10.1080/09715010.2012.721183

9. Chenga B, Yu Y (2012) CFD simulation and optimization for lateral diversion and intake pumping stations. J Procedia Eng 28:122-127. https://doi.org/10.1016/j.proeng.2012.01.693

10. Rajendran VP, Patel VC (2000) Measurement of vortices in model pump-intake bay by PIV. J Hydraul Eng 126:322-334. https://doi. org/10.1061/(ASCE)0733-9429(2000)126:5(322)

11. Turbo machinery Society of Japan (2005) Standard method for model testing the performance of a pump sump, TSJ S002. Tokyo, Japan

12. Choi J, Choi Y, Kim C, Lee Y (2010) Flow uniformity in a multiintake pump sump model. J Mech Sci Technol 24:1389-1400. https://doi.org/10.1007/s12206-010-0413-5

13. Hecker GE, Padmanabhan M (1984) Scale effects in pump sump models. J Hydraul Eng 110:1540-1556. https://doi.org/10.1061/ (ASCE)0733-9429(1984)110:11(1540)

14. Odgaard AJ (1986) Free-surface air core vortex. J Hydraul Eng 112:610-620. https://doi.org/10.1061/ (ASCE)0733-9429(1986)112:7(610)
15. Yildirim N, Kocabas F (2002) Prediction of critical submergence for an intake pipe. J Hydraul Res 40(4):507-518. https://doi. org/10.1080/00221680209499892

16. Ansar M, Nakato T (2001) Experimental study of 3D pump-intake flows with and without cross flow. J Hydraul Eng 127:825-834. https://doi.org/10.1061/(ASCE)0733-9429(2001)127:10(825)

17. Yildirim N, Kocabaş F, Gülcan S (2000) Flow-boundary effects on critical submergence of intake pipe. J Hydraul Eng 126:288-297. https://doi.org/10.1061/(ASCE)0733-9429(2000)126:4(288)

18. Yildirim $\mathrm{N}$ (2004) Critical submergence for a rectangular intake. J Hydraul Eng 130:1195-1210. https://doi.org/10.1061/ (ASCE)0733-9399(2004)130:10(1195)

19. Liu HF, Liptak G (1997) Environmental Engineer's Handbook, 2nd edn. CRC Press, Florida, USA

20. Sodre JR, Parise JAR (1997) Friction factor determination for flow through finite wire-mesh woven-screen matrices. J Fluids Eng 119:847-851. https://doi.org/10.1115/1.2819507

21. Bussiere W, Rochette D, Clain S, Andre P, Renard JB (2017) Pressure drop measurements for woven metal mesh screens used in electrical safety switchgears. Int J Heat Fluid Flow 65:60-72. https://doi.org/10.1016/j.ijheatfluidflow.2017.02.008

22. Costa SC, Barrutia H, Esnaola J, Tutar M (2013) Numerical study of the pressure drop phenomena in wound woven wire matrix of a stirring regenerator. J Energy Convers Manag 67:57-65. https ://doi.org/10.1016/j.enconman.2012.10.014

23. Wu WT, Liu JF, Li WJ, Hsieh WH (2005) Measurement and correlation of hydraulic resistance of flow through woven metal screens. Int J Heat Mass Transf 48:3008-3017. https://doi. org/10.1016/j.jijheatmasstransfer.2005.01.038

24. Yangpeng L, Guoqiang X, Luo X, Jiandong M, Haiwang L (2015) Effect of porosity on flow behavior and heat transfer characteristics of sintered woven wire mesh structures. In: Proceeding of the ASME turbo expo 2015: turbine technical conference and exposition, International Gas Turbine Institute, Montreal, Canada. doi:https://doi.org/10.1115/GT2015-42734

25. Zhan J, Wang B, Yu L, Li Y, Tang L (2012) Numerical investigation of flow patterns in different pump intake systems. J Hydrodyn 24:873-882. https://doi.org/10.1016/S1001-6058(11)60315-6

26. Tokyay TE, Constantinescu SG (2006) Validation of a largeeddy simulation model to simulate flow in pump intakes of realistic geometry. J Hydraul Eng 132:1303-1315. https://doi. org/10.1061/(ASCE)0733-9429(2006)132:12(1303)

27. Hinze JO (1975) Turbulence, 2nd edn. McGraw-Hill, University of Michigan, USA

28. Cebeci T, Smith AMO (1974) Analysis of turbulent boundary layers. Academic press, New York, USA

29. Shih H, Liou W, Shabbir A, Yang Z, Zhu J (1995) A new k- $\varepsilon$ eddy viscosity model for high Reynolds number turbulent flows. J Comput Fluids 24:227-238. https://doi.org/10.1016/0045-7930(94)00032-T

30. Muzaferija S (1999) A two-fluid Navier--Stokes solver to simulate water entry. In: Proceedings of 22nd symposium on naval architecture. National Academy Press.

31. ANSYS-FLUENT Documentation (2011) Ver. 14. ANSYS Inc.

32. Chow VT (1959) Open-channel hydraulics, international student edition. McGraw-Hill, New York, USA

33. Bahrainian SS, Daneh Dezfuli A, Noghrehabadi A (2015) Unstructured grid generation in porous domains for flow simulations with discrete-fracture network model. Transp Porous Media 109:693709. https://doi.org/10.1007/s11242-015-0544-3

34. Fredrich J (2014) Centrifugal pumps, 3rd edn. Springer, New York, USA

Publisher's Note Springer Nature remains neutral with regard to jurisdictional claims in published maps and institutional affiliations. 